\title{
Daily Functioning and Quality of Life of Patients One Year Post Stroke: A Comparison of Two Different Follow-Up Care Programmes
}

\author{
Leonie de Weerd ${ }^{\mathrm{a}, \mathrm{d}}$, Arenda Krol ${ }^{\mathrm{b}}$, Wijnand A.F. Rutgers ${ }^{\mathrm{c}}$, \\ Klaas H. Groeniera, Klaas van der Meer ${ }^{\mathrm{a}}$
}

\begin{abstract}
Background: An observational study to examine whether a new follow-up care programme (ATC) specifically aimed at conservation of daily functioning, quality of life and activities realizes better outcomes in stroke patients compared to conventional (ORP) follow-up care.
\end{abstract}

Methods: A total of 93 stroke patients who followed the ATC follow-up care programme or had conventional follow-up care were interviewed at home one-year post stroke using the Barthel Index and RAND-36 questionnaires and a questionnaire about their way of life and medication use. People aged under 60 , Barthel $<10$ or with haemorrhage were excluded.

Results: In this study 25\% (ATC) and 29\% (ORP) of patients experienced more limitations in activities after one year. In the ATC group the decrease is related to ADL independence and loss of social contacts. ADL independence is correlated with a better quality of life. Health-related quality of life was identical in the two groups. It was observed in both groups that quitting or doing less activities is significantly related to a diminished quality of life. There is no significant difference between the groups in terms of medicine use or follow-up care. More patients visit day centres in the ATC group.

Conclusions: No major differences in outcome could be found between the two groups. A relationship between doing diverse activities and quality of life was found in both groups. Perhaps studying

\footnotetext{
Manuscript accepted for publication February 18, 2013

${ }^{a}$ Department of General Practice, University of Groningen, University Medical Center Groningen, Antonius Deusinglaan 1, 9713 AV Groningen, The Netherlands

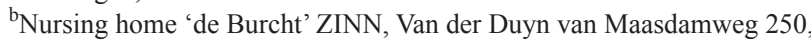
9602 VT Hoogezand, The Netherlands

${ }^{\mathrm{c}}$ Department of Neurology, Martini Hospital Groningen, Van

Swietenplein 1, 9700 RM Groningen, The Netherlands

${ }^{\mathrm{d}}$ Corresponding author: Leonie de Weerd, Antonius Deusinglaan 1, 9713

AV, Groningen, The Netherlands. Email: 1.de.weerd@umcg.nl
}

doi: http://dx.doi.org/10.4021/jnr182e the individual needs of stroke patient would be more effective than a standard follow-up care programme. This needs further investigation.

Keywords: Stroke; Rehabilitation; Functioning; Quality of life; Secondary prevention; Aftercare

\section{Introduction}

Each year, 19.000 men and 22.000 women in the Netherlands have strokes $[1,2]$. Absolute lifetime risk of stroke is similar in men and women [3]. The average age of patients having a stroke is seventy years in men and seventy-five in women [4]. Twenty-five percent of all patients die in the first year after stroke [5].

The post-stroke period can be divided into three phases: the acute phase, the rehabilitation phase and the chronic phase. This distinction is important because treatment and patient support are different at each phase [6]. Our study concerns the chronic phase, which starts approximately six months after a stroke, where acceptance and coping with persistent disabilities plays a prominent role [6].

Strokes change patients' lives in many different ways, not only physically, but also emotionally, psychically, cognitively and socially [7]. This influences quality of life (QOL). As stroke mortality declines, more patients have to live with the consequences of stroke. Therefore, improving QOL and paying more attention to follow-up care is increasingly important [7].

After discharge from hospital, stroke patients return home or need rehabilitation in a nursing home or rehabilitation clinic. The present study is about patients who rehabilitated in a nursing home and returned home after rehabilitation. When patients finally return home a lot of things have changed. It is therefore important to also pay attention to follow-up care after discharge from a nursing home.

In Groningen, the Netherlands, we have developed a new follow-up care programme. Figure 1 provides the old follow-up care programme (ORP) and Figure 2 shows the new ATC programme (Ambulant Treatment team for CVA- 


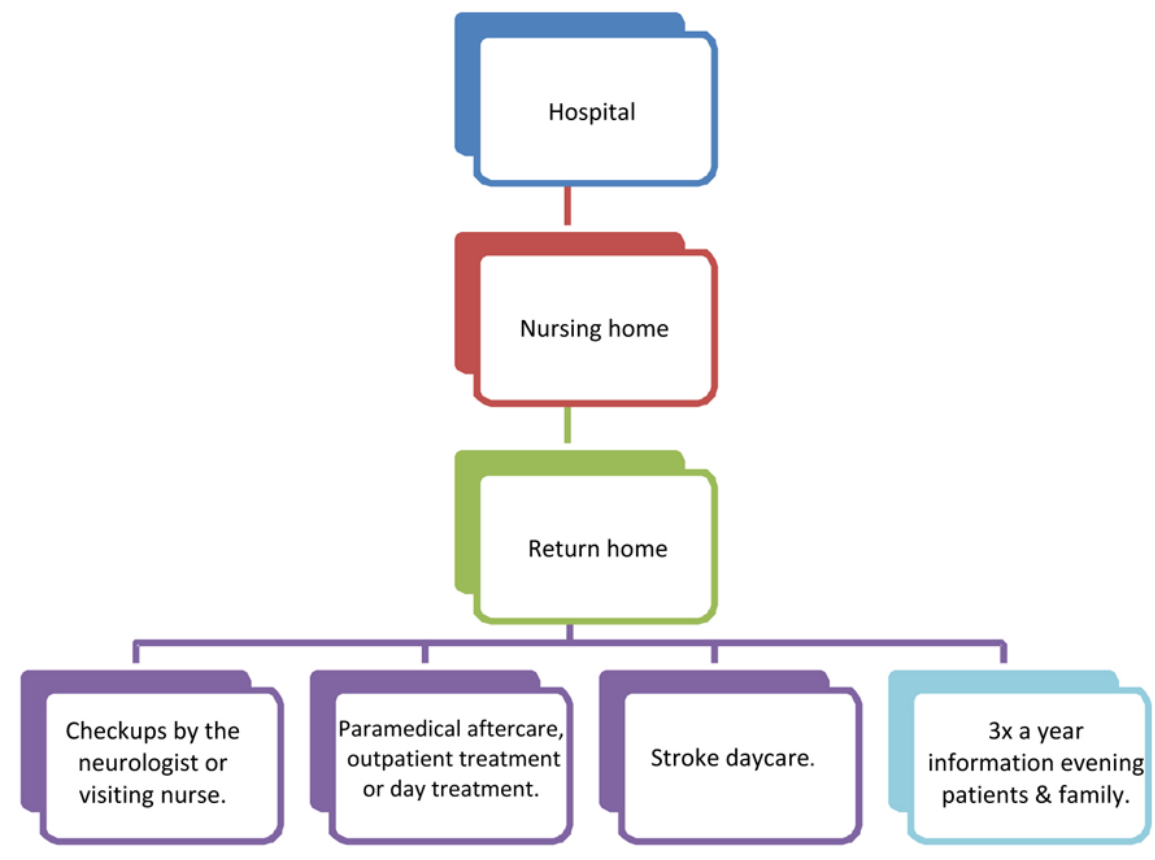

Figure 1. The conventional follow-up care (ORP).

patients). In the ATC programme there are two pathways, namely complex and non-complex. The complex pathway concerns patients who cannot be treated in general practice, patients who have invalidating cognitive or behavioural problems after stroke or those where there is no stable home environment, or where there is doubt whether the teached behaviours in rehabilitation will be applied at home. Patients in the complex pathway are guided for a year. Where there are problems, the ATC team tries to find a solution in cooperation with the patient or his/her GP. One of the professionals in the ATC team visits the patients regularly and the whole team gives advice on daily life and advice about the required follow-up care to the GPs. When necessary, the ATC team can treat certain conditions like depression, but also teach patients to go shopping, visiting or going on holidays again.

The ATC programme was designed because there were indications that when patients are finally at home they face other problems than with rehabilitation and that a lot of stroke patients were not seeking help for many of the problems they experienced at home. With ATC guidance these problems are made clear earlier and it is easier to give advice. Major difference between the two programmes is the frequency of follow up and contacts between patients and a professional in which support and treatment can be given.

The purpose of this study is to determine whether the ATC follow-up care programme realizes a better outcome compared to the ORP follow-up care. This was done by comparing the wellbeing of patients who were treated by the ATC team one year post stroke to patients who had followed the ORP. Wellbeing includes physical functioning, QOL, secondary prevention and changes in life habits.

\section{Patients and Methods}

\section{Study design}

The study includes all the ischemic stroke patients admitted to the Heymanscentrum nursing home in Groningen, between July 2005 and July 2006(the ORP group) and between November 2006 and November 2007(the ATC group). A total of 190 (93 ORP and 97 ATC) patients were included. The exclusion criteria for patients were: a) being under 60 , to create a more homogenous group, because younger patients have different social life and the impact of diminished functioning is possibly much greater than in older patients; b) haemorrhagic stroke, because these patients have a worse prognosis [8] and different risk profile [9]; and c) patients with a Barthel score under 10. The MEC (medical ethical committees) of the Martini Hospital approved this study (17 January 2008). Informed consent was obtained from all patients.

After informed consent, clinical details - including stroke severity, co-morbidity, risk factors before stroke, use of medication and demographic information - were obtained from medical records. Stroke severity was determined by the National Institute of Health Stroke Scale examination at hospital admittance.

One year post stroke all patients were visited at home by a medical practitioner. Patients were interviewed in person by a trained medical practitioner and standardized question- 


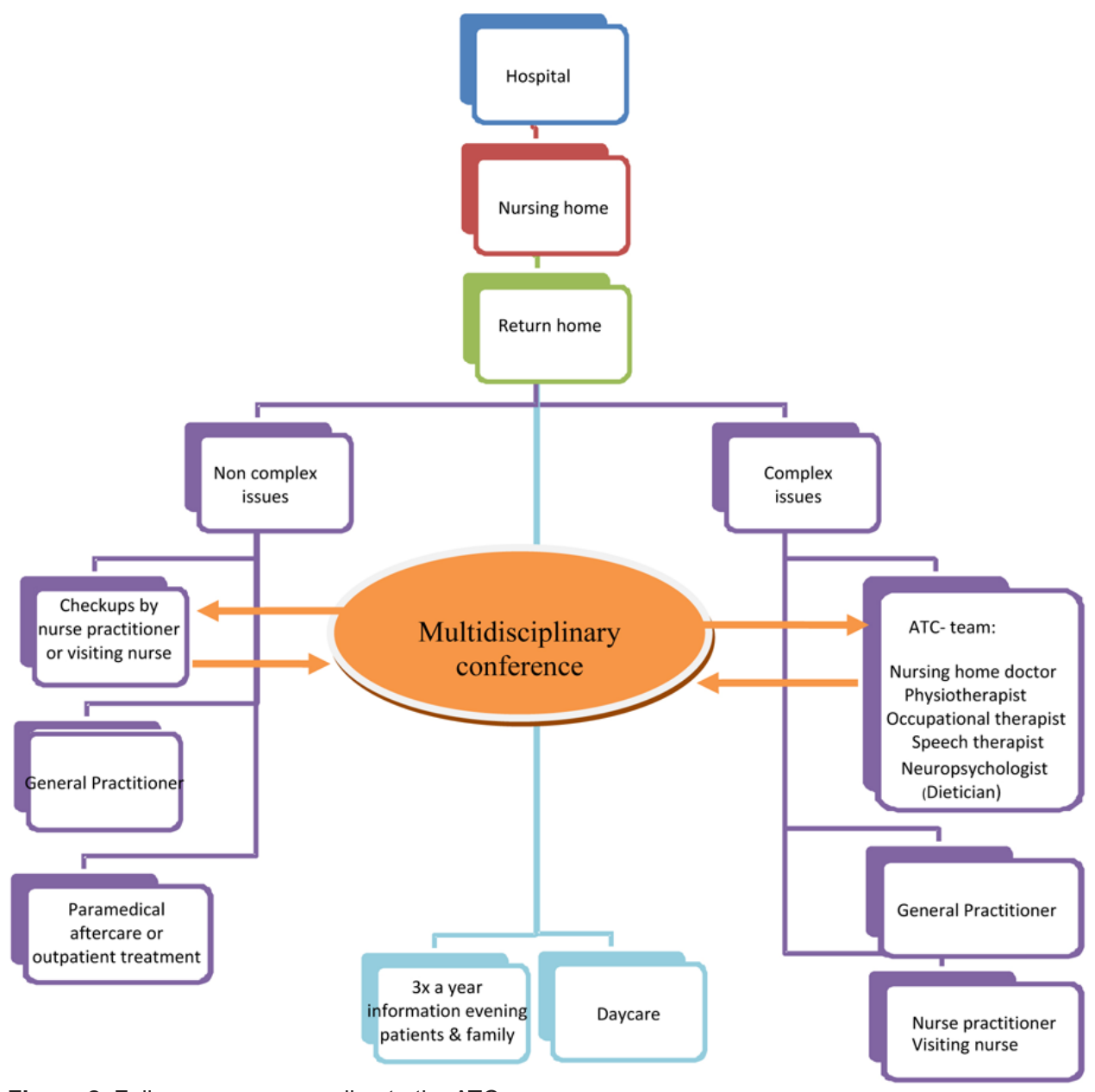

Figure 2. Follow-up care according to the ATC programme.

naires were administered.

\section{Measures at 12 months}

The Barthel Index (BI) was used to assess disability in our patients. The BI measures the level of independence in ADL and yields a score ranging from 0 (functionally dependent) to 20 - 21 (functionally independent). Patients are given three points for eating independently in this questionnaire, rather than two points. The sensitivity and reliability of the BI are high for stroke patients [10-12].

To measure health-related quality of life (HRQOL) we used the RAND-36. The RAND-36 consists of 36 questions and comprises 8 health-scales (physical function (FF), role limitations - physical (Rlf), social functioning (SF), role limitations - emotional (Rle), bodily pain (BP), general health $(\mathrm{GH})$, vitality (Vit) and mental health $(\mathrm{MH})$ ). The health scales range from 0 (poor HRQOL) to 100 (good HRQOL). This is based on the summated ratings method. The RAND36 is a reliable and valid measure for determining HRQOL in stroke patients [13-15]. The HRQOL in this study was compared to the HRQOL of the Dutch elderly population [15].
In addition, patients were asked about changes in habits and daily occupations because of stroke, such as smoking, alcohol consumption, housekeeping, physical exercise, hobbies, reading, visiting family and friends, membership of clubs or associations and going on holiday. We also asked about their use of medication, if they had contact with their GPs, neurologists, nurse practitioners or assistants, and their reason for this contact. They were also asked about rehabilitation: whether they had any and how many times they had physiotherapy, speech therapy, occupational therapy, home help, day-centre care and admittance to hospital.

\section{Statistical analysis}

SPSS 15 for Windows was used for statistical analysis. Statistical significance was set at $\mathrm{P}<0.05$ (2-sided). For comparisons between groups we used the non-parametric tests: Mann-Whitney, Kruskall-Wallis and Analysis of variance (ANOVA) using the Rank Transform method. The Rank Transform method consists of replacing the observations by their ranks in the combined sample and performing one of the standard analysis of variance procedures on these ranks 


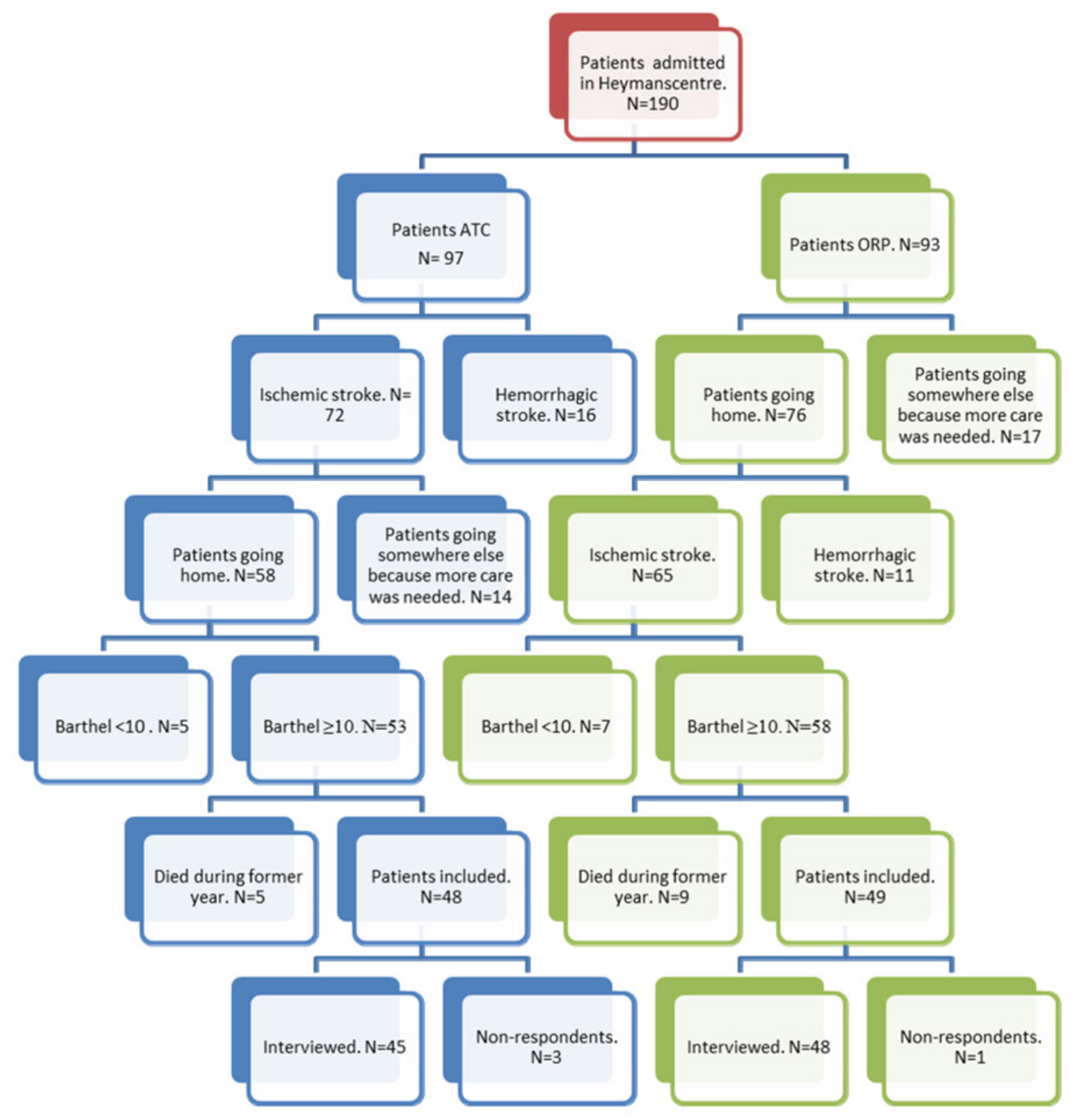

Figure 3. Patient selection flow chart.

[16]. Fisher's exact test was used for categorical variables.

To describe the number of patients who changed their habits due to stroke, their responses were categorized into 'more', 'less', 'as much as before' or 'quit'.

Despite the relatively large number of statistical tests applied, we decided not to correct for 'multiple testing' (for instance by means of the Bonferroni method). Instead, the Pvalues are simply presented as an indication of the strength of the evidence.

\section{Results}

\section{Baseline characteristics}

A total of 190 patients were found to have had an ischemic stroke. Eventually, ninety-three interviews (ATC $\mathrm{N}=45$, ORP N =48) were conducted (Fig. 3 ).
Detailed baseline characteristics of the study population are provided in Table 1 . There are no significant differences in the characteristics of the two groups.

\section{Level of dependence according to Barthel Index}

When patients were admitted in the nursing home, 24\% of the ATC group and $15 \%$ of the ORP group were severely till totally dependent (BI: 0 till 10). One year after discharge 3 patients of the ATC and 1 patient of the ORP were severely or totally dependent. Most patients were not dependent at all (BI > 19) (ATC: 56\%, ORP: 58\%) or only slightly dependent (BI 15 till 20) (ATC: 38\%, ORP: 35\%).

Almost $38 \%$ of the ATC group and $40 \%$ of the ORP group scored the same at discharge and one year after discharge. Thirty-eight percent (ATC) and 31\% (ORP) had better scores after one year. Twenty-five percent (ATC) and 29\% (ORP) had worse scores. Progress in ADL independen- 
Table 1. Baseline Characteristics of the Study Population

\begin{tabular}{|c|c|c|c|}
\hline Variables & $\operatorname{ATC}(\%)$ & ORP (\%) & $\mathbf{P} *$ \\
\hline Patients included & 45 & 48 & \\
\hline \multicolumn{4}{|l|}{ Gender } \\
\hline Men & $22(49)$ & $17(35)$ & \\
\hline Women & $23(51)$ & $31(65)$ & \\
\hline Age, average (range) & $78(61-92)$ & $77(60-89)$ & \\
\hline \multicolumn{4}{|l|}{ Living situation } \\
\hline Living alone & $21(47)$ & $30(62.5)$ & \\
\hline Living with a partner & $24(53)$ & $18(37.5)$ & \\
\hline Brain hemisphere & & & 0.351 \\
\hline Left side & $19(42)$ & $27(56)$ & \\
\hline Right side & $22(49)$ & $21(44)$ & \\
\hline Unknown & $4(9)$ & - & \\
\hline NIHSS, average (range) & $5(0-23)$ & $5(0-22)$ & 0.522 \\
\hline \multicolumn{4}{|c|}{ Risk factors present before stroke } \\
\hline No risk factors & $7(16)$ & $3(6)$ & 0.189 \\
\hline Hypertension & $24(53)$ & $17(43)$ & 0.082 \\
\hline Hypercholesterolemia & $9(20)$ & $7(14)$ & 0.489 \\
\hline Diabetes & $5(11)$ & $8(20)$ & 0.440 \\
\hline Cardiac embolus & $11(24)$ & $12(22)$ & 0.951 \\
\hline Smoking & $10(22)$ & - & \\
\hline \multicolumn{4}{|l|}{ History } \\
\hline No history & $7(16)$ & $3(6)$ & 0.189 \\
\hline Ischemic heart disease & $13(29)$ & $7(15)$ & 0.093 \\
\hline Stroke/TIA & $12(27)$ & $14(29)$ & 0.788 \\
\hline Atrial fibrillation & $7(16)$ & $12(25)$ & 0.259 \\
\hline Heart failure & $2(4)$ & $4(8)$ & 0.678 \\
\hline COPD & $4(11)$ & $9(19)$ & 0.303 \\
\hline Depression & $4(9)$ & $2(4)$ & 0.425 \\
\hline
\end{tabular}

${ }^{*}$ Fisher's exact test.

cy after one year did not differ significantly between the two groups $(\mathrm{P}=0.457)$.

Being more dependent was related to diminishing daily occupations. This was significant in housekeeping, physical activity and hobbies in both groups. An experienced decline in QOL is not related to being more dependent (Table 2).

There is no significant difference between follow-up care and BI (Table 2). Only ATC group patients with district nursing service experienced worse BI than patients without district nursing service.
The Rank Transform ANOVA was used to investigate whether there were any interaction effects between the ATC and ORP groups and gender, changes in habits, daily occupations, use of medication, the frequency of contact with GPs, neurologists or rehabilitation with respect to the BI scores. There were no significant interaction effects (Table 2).

\section{Health-related quality of life (RAND-36)}

Table 3 presents the comparison between the HRQOL of 
Table 2. Functioning (BI), One Year After Discharge According to Demographic Factors, Change in Activities and Follow-Up Care

\begin{tabular}{|c|c|c|c|c|c|c|c|}
\hline \multirow{2}{*}{ Variables } & \multicolumn{4}{|c|}{ ATC group } & \multicolumn{3}{|c|}{ ORP group } \\
\hline & $\mathbf{N}$ & Median (range) & $\mathbf{P}^{*}$ & $\mathbf{N}$ & Median (range) & $\mathbf{P}^{*}$ & $\mathbf{P}^{\#}$ \\
\hline \multicolumn{8}{|l|}{ Gender $^{2}$} \\
\hline Male & 22 & $20(8-21)$ & 0.467 & 17 & $19(2-21)$ & 0.018 & 0.434 \\
\hline Female & 23 & $20.5(7-21)$ & & 31 & $21(17-21)$ & & \\
\hline \multicolumn{8}{|l|}{ Social situation ${ }^{2}$} \\
\hline Living alone & 21 & $20(8-21)$ & 0.820 & 18 & $20(2-21)$ & 0.834 & 0.619 \\
\hline Living with partner & 24 & $20.5(7-21)$ & & 30 & $20(16-21)$ & & \\
\hline \multicolumn{8}{|l|}{ Stroke location ${ }^{2}$} \\
\hline Left side & 19 & $21(8-21)$ & 0.075 & 27 & $20(11-21)$ & 0.282 & 0.300 \\
\hline Right side & 22 & $19(7-21)$ & & 21 & $20(2-21)$ & & \\
\hline \multicolumn{8}{|l|}{ Housekeeping ${ }^{1}$} \\
\hline More & & & 0.000 & & & 0.014 & 0.619 \\
\hline As much as before & 16 & $21(18-21)$ & & 15 & $21(17-21)$ & & \\
\hline Less & 19 & $19(16-21)$ & & 26 & $20(13-21)$ & & \\
\hline Quit & 10 & $17.5(7-21)$ & & 7 & $17(2-20)$ & & \\
\hline \multicolumn{8}{|l|}{ Physical activity ${ }^{1}$} \\
\hline More & & & 0.012 & & & 0.014 & 0.407 \\
\hline As much as before & 16 & $21(18-21)$ & & 17 & $21(13-21)$ & & \\
\hline Less & 25 & $19(15-21)$ & & 26 & $19(11-21)$ & & \\
\hline \multirow{2}{*}{\multicolumn{8}{|c|}{ Hobbies $^{1}$}} \\
\hline & & & & & & & \\
\hline More & 1 & & 0.014 & & & 0.043 & 0.051 \\
\hline As much as before & 21 & $21(16-21)$ & & 21 & $21(13-21)$ & & \\
\hline Less & 18 & $20(8-21)$ & & 16 & $19.5(16-21)$ & & \\
\hline Quit & 5 & $17(7-19)$ & & 11 & $20(2-20)$ & & \\
\hline \multicolumn{8}{|l|}{ Visiting $^{1}$} \\
\hline More & & & 0.000 & & & & \\
\hline As much as before & 20 & $21(18-21)$ & & 31 & $20(13-21)$ & 0.214 & 0.551 \\
\hline Less & 19 & $20(16-21)$ & & 16 & $20(11-21)$ & & \\
\hline Quit & 6 & $11.5(7-19)$ & & 1 & 2 & & \\
\hline \multicolumn{8}{|c|}{ Experienced quality of life ${ }^{2}$} \\
\hline The same & 22 & $21(8-21)$ & 0.079 & 21 & $19(13-21)$ & 0.367 & 0.331 \\
\hline Diminished & 22 & $19(7-21)$ & & 27 & $20(2-21)$ & & \\
\hline \multicolumn{8}{|l|}{ GP contact ${ }^{2}$} \\
\hline No & 3 & $21(19-21)$ & 0.364 & & & & \\
\hline Yes & 42 & $20(7-21)$ & & & & & \\
\hline$>10$ times & & & & 26 & $20(2-21)$ & 0.864 & \\
\hline \multirow{2}{*}{\multicolumn{8}{|c|}{ Neurologist contact ${ }^{2}$}} \\
\hline & & & & & & & \\
\hline No & 11 & $20(17-21)$ & 0.972 & 5 & $19(13-21)$ & 0.719 & \\
\hline Yes & 26 & $20.5(8-21)$ & & 43 & $20(2-21)$ & & \\
\hline Physiotherapy $^{2}$ & & & & & & & \\
\hline No & 13 & $21(15-21)$ & 0.070 & 34 & $20(2-21)$ & 0.136 & 0.264 \\
\hline Yes & 32 & $19(7-21)$ & & 14 & $18.5(11-21)$ & & \\
\hline Speech therapy ${ }^{2}$ & & & & & & & \\
\hline No & 31 & $19(7-21)$ & 0.216 & 32 & $20(2-21)$ & 0.320 & 0.698 \\
\hline Yes & 14 & $21(8-21)$ & & 16 & $20(16-21)$ & & \\
\hline Occupational $^{2}$ therapy & & & & & & & \\
\hline No & 28 & $21(7-21)$ & 0.105 & 34 & $20(13-21)$ & 0.127 & 0.160 \\
\hline Yes & 17 & $19(8-21)$ & & 14 & $19(2-21)$ & & \\
\hline District nursing services & & & & & & & \\
\hline No & 29 & $21(8-21)$ & 0.000 & 24 & $20(2-21)$ & 0.470 & \\
\hline Yes & & & & 19 & $20(11-21)$ & & \\
\hline More & 15 & $18(7-21)$ & & & & & \\
\hline Less & & & & 5 & $21(18-21)$ & & \\
\hline Local Authority home h & & & & & & & \\
\hline No & 19 & $19(7-21)$ & 0.766 & 18 & $20(16-21)$ & 0.374 & 0.780 \\
\hline Yes & 25 & $20(8-21)$ & & 30 & $20(2-21)$ & & \\
\hline Day center ${ }^{2}$ & & & & & & & \\
\hline No & 33 & $21(7-21)$ & 0.103 & 43 & $20(2-21)$ & 0.222 & 0.425 \\
\hline Yes & 12 & $19(8-21)$ & & 5 & $20(17-21)$ & & \\
\hline Hospital admittance ${ }^{2}$ & & & & & & & \\
\hline No & 38 & $20(7-21)$ & 0.780 & 38 & $20(13-21)$ & 0.496 & 0.316 \\
\hline Yes & 7 & $19(17-21)$ & & 10 & $19.5(2-21)$ & & \\
\hline
\end{tabular}

* Kruskall-Wallis1 and Mann-Whitney2 test, \# Interaction rank transform ANOVA. 
Table 3. Rand-36 Comparison in the Two Study Groups

\begin{tabular}{llll}
\hline & ATC & ORP & \multirow{2}{*}{$\mathbf{P}^{*}$} \\
\cline { 2 - 3 } Rand-36 & Median (range) & Median (range) & \\
\hline Physical functioning & $45(0-95)$ & $55(0-95)$ & 0.301 \\
Social functioning & $87.5(25-100)$ & $100(0-100)$ & 0.836 \\
Role limitations - physical & $50(0-100)$ & $25(0-100)$ & 0.012 \\
Role limitations - emotional & $100(33.3-100)$ & $100(0-100)$ & 0.552 \\
Mental Health & $82(12-100)$ & $76(24-100)$ & 0.086 \\
Vitality & $65(0-100)$ & $65(20-100)$ & 0.727 \\
Bodily Pain & $100(34.7-100)$ & $100(10.2-100)$ & 0.673 \\
General Health & $65(15-100)$ & $50(5-100)$ & 0.042 \\
\hline
\end{tabular}

*Mann-Whitney test.

the ATC and the ORP groups. HRQOL is nearly identical in these two groups, except for two health scales. The ATC group has significantly better HRQOL for the 'role limitations - physical' and 'general health' health scales.

Two aspects of the RAND-36 were related to level of dependence in personal activities of daily living (BI). There is a high correlation with the 'physical functioning' health scale (ATC: $\mathrm{R}=0.850$; ORP: $\mathrm{R}=0.593$ ) and a moderate correlation with 'role-limitations physical' health scale $(\mathrm{R}=$ 0.329 ) in the ATC group.

Tables 4 and 5 present the relationship between HRQOL and change in activities. Patients who stopped or reduced activities such as housekeeping, physical exercise, hobbies or visiting presented significantly worse HRQOL.

We also investigated whether there was an interaction effect between the groups and the change in activities in the RAND-36 (Table 6). There is only one significant interaction effect between housekeeping and the ATC and ORP groups for the RAND-36 $(\mathrm{P}=0.046)$.

\section{Daily occupations}

Quitting or doing less of certain activities such as housekeeping, physical activity, hobbies and visiting is significantly related to physical functioning and HRQOL for both groups. The percentages of patients who had to stop or diminish activities are presented in Table 7.

\section{Medication}

The use of medication is important in secondary prevention. One year post stroke, 51\% (ATC) and 36\% (ORP) used the same medication as at discharge from hospital.
One year post stroke, $60 \%$ of the ATC group used aspirin. On discharge from hospital, this percentage was $69 \%$. Thirty-six percent used aspirin and dipyridamole in combination. Thirty-one percent of the ATC patients used acenocoumarol. Two percent used no blood-thinning medication at all.

In the ORP group, $8 \%$ used no blood-thinning medication at all. Sixty-nine percent used aspirin. Nineteen percent used aspirin and dipyridamole in combination. Twenty-one percent used acenocoumarol.

Another important group of drugs are the cholesterollowering medications. Use of simvastatin decreased over one year. No cholesterol-lowering medication was used in $33 \%$ of the ATC and $29 \%$ of the ORP group.

In both groups, $80 \%$ of patients use antihypertensive medication after stroke. The most frequently used medication is a thiazide diuretic ( $42 \%$ ATC and $38 \%$ of the ORP group). Forty-four percent of the patients said their blood pressure was never measured in the year preceding the interview.

There are no significant differences in medication use between the two rehabilitation groups.

\section{Follow-up care}

Patients were asked how often they visited their GPs. Seven percent $(\mathrm{N}=3)$ of the ATC group and no-one from the ORP group said they had no contact with their GP. Many patients would like their GP to visit them more often.

Seventy-one percent of the patients from the two groups received physiotherapy. In both groups $30 \%$ had occupational therapy and $30 \%$ had speech therapy.

In the ATC group 33\% had district nursing service, as 


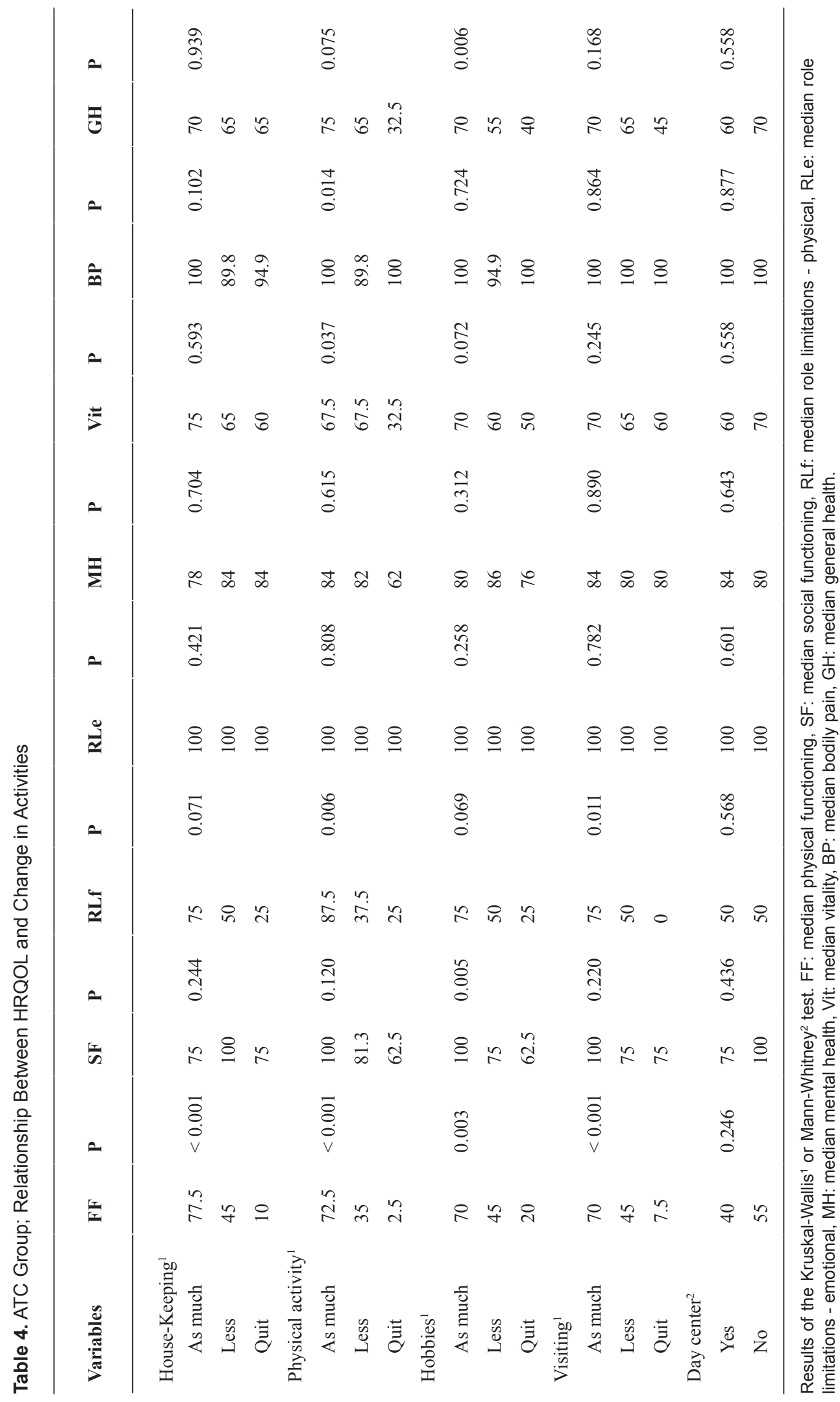




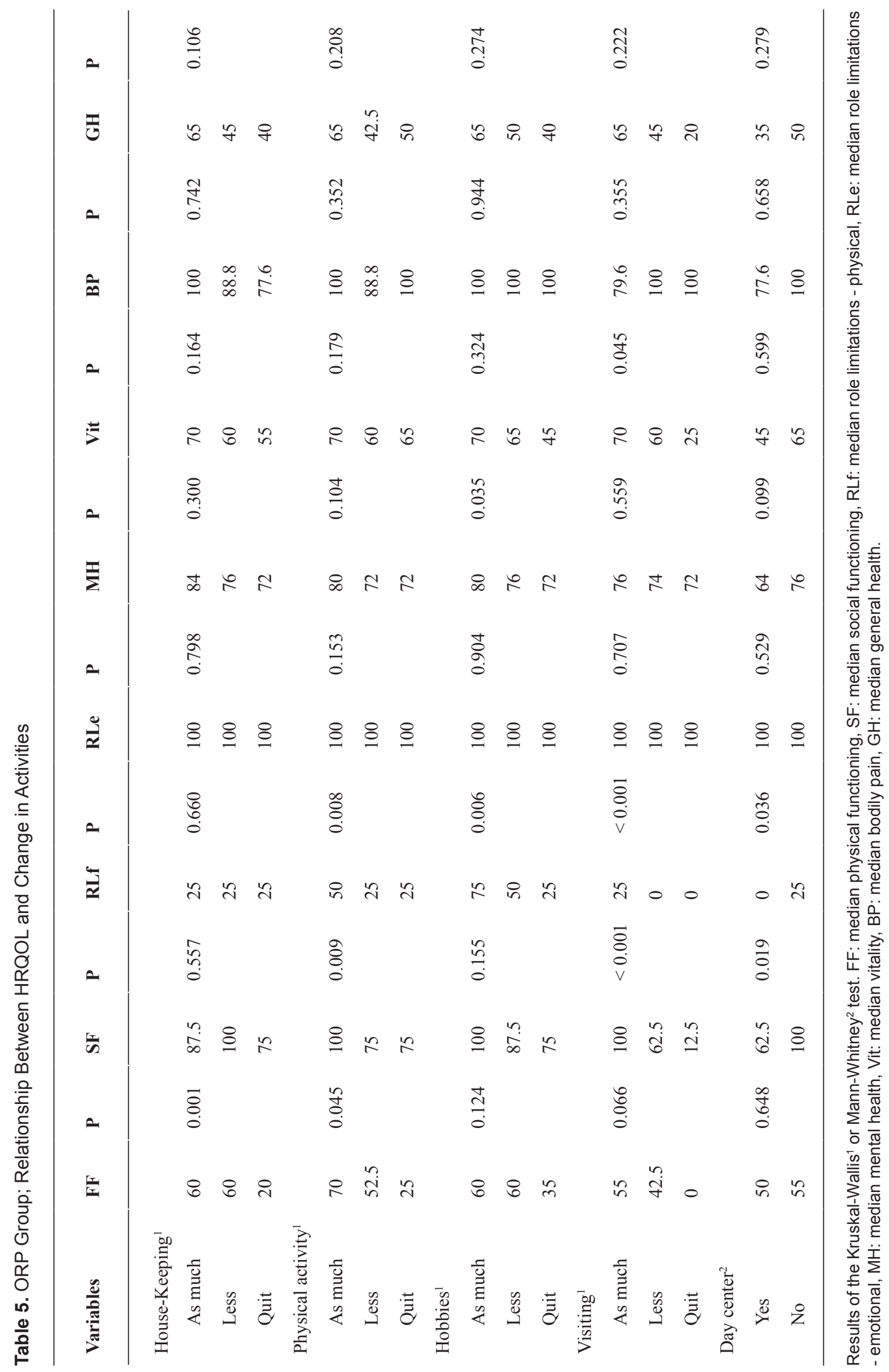


Table 6. RAND-36 Interactions Between the ATC and ORP Groups and Activities

\begin{tabular}{|c|c|c|}
\hline HRQOL & Activities & $\mathbf{P}^{\#}$ \\
\hline \multirow[t]{5}{*}{ Physical functioning } & Housekeeping & 0.046 \\
\hline & Physical activity & 0.128 \\
\hline & Hobbies & 0.164 \\
\hline & Visiting & 0.870 \\
\hline & Day centre & 0.695 \\
\hline \multirow[t]{5}{*}{ Social functioning } & Housekeeping & 0.860 \\
\hline & Physical activity & 0.256 \\
\hline & Hobbies & 0.430 \\
\hline & Visiting & 0.063 \\
\hline & Day centre & 0.141 \\
\hline \multirow[t]{5}{*}{ Role limitations - physical } & Housekeeping & 0.701 \\
\hline & Physical activity & 0.804 \\
\hline & Hobbies & 0.190 \\
\hline & Visiting & 0.142 \\
\hline & Day centre & 0.154 \\
\hline \multirow[t]{5}{*}{ Role limitations - emotional } & Housekeeping & 0.564 \\
\hline & Physical activity & 0.321 \\
\hline & Hobbies & 0.367 \\
\hline & Visiting & 0.892 \\
\hline & Day centre & 0.847 \\
\hline \multirow[t]{5}{*}{ Mental health } & Housekeeping & 0.218 \\
\hline & Physical activity & 0.312 \\
\hline & Hobbies & 0.607 \\
\hline & Visiting & 0.808 \\
\hline & Day centre & 0.131 \\
\hline \multirow[t]{5}{*}{ Vitality } & Housekeeping & 0.732 \\
\hline & Physical activity & 0.079 \\
\hline & Hobbies & 0.718 \\
\hline & Visiting & 0.412 \\
\hline & Day centre & 0.882 \\
\hline \multirow[t]{5}{*}{ Bodily pain } & Housekeeping & 0.634 \\
\hline & Physical activity & 0.289 \\
\hline & Hobbies & 0.847 \\
\hline & Visiting & 0.565 \\
\hline & Day centre & 0.622 \\
\hline \multirow[t]{5}{*}{ General health } & Housekeeping & 0.351 \\
\hline & Physical activity & 0.281 \\
\hline & Hobbies & 0.424 \\
\hline & Visiting & 0.834 \\
\hline & Day centre & 0.471 \\
\hline
\end{tabular}

\# Interaction rank transform ANOVA. 
Table 7. Change in the Frequency of Daily Occupations

\begin{tabular}{|c|c|c|c|}
\hline Daily Occupations & $\operatorname{ATC}(\%)$ & ORP (\%) & $\mathbf{P}^{*}$ \\
\hline \multicolumn{4}{|l|}{ Housekeeping } \\
\hline The same & 35.6 & 31.3 & 0.459 \\
\hline Less & 42.2 & 54.2 & \\
\hline Quit & 22.2 & 14.6 & \\
\hline \multicolumn{4}{|l|}{ Physical exercise } \\
\hline The same & 35.6 & 35.4 & 1.000 \\
\hline Less & 55.6 & 54.2 & \\
\hline Quit & 8.9 & 10.4 & \\
\hline \multicolumn{4}{|l|}{ Hobbies } \\
\hline More & 2.2 & 0 & 0.328 \\
\hline The same & 46.7 & 43.8 & \\
\hline Less & 40.0 & 33.3 & \\
\hline Quit & 11.1 & 22.9 & \\
\hline \multicolumn{4}{|l|}{ Visiting } \\
\hline The same & 44.4 & 64.6 & 0.041 \\
\hline Less & 42.2 & 33.3 & \\
\hline Quit & 13.3 & 2.1 & \\
\hline \multicolumn{4}{|l|}{ Holidays } \\
\hline The same & 62.2 & 45.8 & 0.047 \\
\hline Less & 17.8 & 10.4 & \\
\hline Quit & 20.0 & 43.8 & \\
\hline
\end{tabular}

${ }^{*}$ Fisher's exact test.

did $45 \%$ of the ORP. Forty-three percent of the ATC group and $38 \%$ of the ORP group did not receive local authority home help.

In the ATC group $27 \%$ of the patients visited day centres. Only $10 \%$ of the ORP group visited day centre. Fourteen percent (ATC) and 18\% (ORP) had suffered from another stroke.

\section{Discussion}

The aim of this study was to compare the wellbeing one year post stroke of patients treated by the ATC team with patients who had followed the ORP to determine if the ATC followup care realizes better outcomes.

The two groups were readily comparable because there were no significant differences in their NIHSS, age, stroke location and risk factors.

This study has several limitations. The study groups were relatively small because of selection criteria. To make stronger generalizations, the study group should be larger and patients from multiple nursing homes should be studied. The participants were distributed to two treatments in the basis of time entering the study. Although the practitioners in the different programs were the same, we could not completely rule out the confounding factor time entering the rehabilitation programs. Furthermore, the study groups had a very high mean age, thus decline in functioning is possibly partially due to normal aging. Finally, patients who refused to participate in this study were not considered. These patients told us that they were doing fine and that a visit was not necessary. Theoretically, these patients could be those whose physical and psychological functioning is very bad.

One of this study's strengths is the method of data acquisition. We visited patients at home to complete the questionnaires together. A lot of information is obtained through conversation, not only through the actual talking but also by being able to demonstrate. Another strength is the fact that one researcher visited all the patients and that we used standardized questionnaires. This avoids different interpretation of the results.

Our research showed no significant difference in ADL independence after one year between the ATC group and the ORP group. Like other studies [17], there is a relationship between ADL independence and daily occupations in both groups. Paying attention to this in rehabilitation is important 


\section{$[18,19]$.}

In the ATC group there is a relationship between ADL independence and loss of social contacts. This has also been observed in other studies [20, 21]. In the ORP group no relationship was found. We expected the opposite because more attention is paid to this aspect in the ATC programme. A possible explanation is that when more attention is paid to this problem, people experience more loss of social contacts. Life satisfaction is significantly related to social activity and ADL independence [22-24], this should therefore receive extra attention in rehabilitation.

HRQOL was studied with the RAND-36. Unfortunately, the HRQOL was only measured one year post stroke. HRQOL was nearly identical in the two groups. The ATC group only had better HRQOL in 'role limitations - physical' and 'general health' health. HRQOL and ADL independence were correlated. Worse ADL independence correlates to worse 'physical functioning' and 'role-limitations physical'. Other studies also show such a relationship [25-28]. Physical impairment has a great impact on reintegration of stroke patients in society. HRQOL is raised with improvement in physical state, and patients are more easily reintegrated into society [27].

The HRQOL in both groups was high. The studies of Kauhanen et al (2000) and Carod-Artal et al (2000) report lower HRQOL after one year. They possible studied more severely impaired stroke patients, because they included all ischemic stroke patients. In contrast, in our study the mean age was higher $[25,29]$. In a study by Shyu et al (2009), older ischemic stroke patients were interviewed at home, but these patients seem to have also had lower HRQOL [28].

There was a significant difference between the ATC group and ORP group with respect to holidays and visiting. Patients in the ATC group more frequently reported that their vacation habits were unchanged. This is possibly due to the fact that going on holidays was specifically trained in the ATC rehabilitation. Patients in the ORP group were more often able to continue visiting family and friends. We have no good explanation for this, because the ATC group specifically trained visiting in rehabilitation.

A diminished QOL is significantly related to quitting or doing less of certain activities such as housekeeping, physical activity, hobbies and visiting in both groups. HRQOL could possibly increase further were patients to receive even more support than was given in the ATC rehabilitation to resume different activities. Another option would be to start community-based rehabilitation programmes. This could increase stroke patients' activity levels and give them greater satisfaction [30-33], although this was not found in the ATC group.

There is no significant difference in medication use between the two rehabilitation groups. We would have expected a stricter use of medication in the ATC group because of more intensive assistance.
Although there are no significant differences in medication use, in the ATC group more patients were using the same medicine as they had done on discharge from their nursing homes compared to the ORP group. One year post stroke more patients from the ORP group used no blood-thinning medication at all. Of the ATC group, fewer patients used aspirin, but more used aspirin and dipyridamole in combination, or acenocoumarol. When patients use aspirin, the risk of further stroke decreases by $13-22 \%$ [34]. The use of aspirin is recommended to every stroke patient and patients with atrial fibrillation should use acenocoumarol [35]. When dipyridamole or clopidogrel is added to aspirin, it will result in a relative risk reduction of $16 \%$ for vascular death, stroke or heart attack [36]. All in all, there seems to be better use of blood-thinning medication in the ATC group. Some minor aspects can be adjusted, such as adding dipyridamole to aspirin. However, this only concerns small percentage of patients.

Use of simvastatin decreased over one year. This is possibly due to negative publicity. Less cholesterol-lowering medication is used by the ATC group, though these patients get more assistance in using medicine. Almost everyone should use cholesterol-lowering medication unless life expectancy based on comorbidity is minimal. The risk of cardiovascular disease is reduced by statins, regardless of cholesterol levels. With respect to fatal and non-fatal cardiovascular disease through statin use, an absolute risk reduction of $5-6 \%$ is achieved. Treatment with statins even in elderly patients will reduce the risk of cardiovascular disease $[34,35,37]$.

Eighty percent of patients from both groups used antihypertensive medication, but $44 \%$ said their blood pressure had never been measured in the year preceding the interview. It is important to check blood pressure regularly. A reduction of $5-6 \mathrm{mmHg}$ in diastolic blood pressure or $10 \mathrm{mmHg}$ in systolic pressure results in a $24 \%$ reduction in the chances of stroke recurrence [34].

Seven percent of the ATC group and $0 \%$ of the ORP group reported that they had received no post-stroke contact with their GPs. This could be explained by the fact that patients from the ATC group receive a lot of assistance from others, meaning that GPs are under the impression that contact with them is less necessary.

Turning to follow-up care, many patients (71\% ATC and $71 \%$ ORP) received physiotherapy. Thirty percent of both groups received occupational therapy and 30\% received speech therapy. Follow-up care is very important because early initiation of rehabilitation is related to improved functional outcome and physiotherapy based on different approaches has a greater impact on functional independence than no therapy at all [38-40]. Because patients from ATC group received more specific guidance and therapy we would expect that functioning would be much better than in the ORP group. However, in this study this was not found. 
Harrington (2009) showed that low-cost 'exercise and education' intervention was successful in improving physical integration, when compared with standard care [41].

The same percentage of patients in the ATC and ORP group received district nursing service and local authority home help. Although the assistance provided for the two groups is different, there is no difference in using these two services. A lot more patients from the ATC group visited a day centre. This is probably due to the fact that patients from the ATC group receive more information about day centre care and are encouraged use it.

Fourteen percent (ATC) and 18\% (ORP) suffered from another stroke. In a study by Appelros et al (2003), 9\% of survivors experienced another stroke within one year [42]. This percentage is lower than our findings. The number of patients with stroke recurrence is too small to investigate whether there is a relationship between the quality of followup care and the occurrence of a second stroke.

Mortality differs slightly between the two groups (ATC 9.4\%, ORP $16.6 \%$ ), but is still relatively low. Mortality in other studies is about $30 \%[5,43,44]$. Mortality is probably low because the severity of stroke was also low in terms of NIHSS score on admission to hospital. There is a relationship between higher NIHSS score and higher mortality [45, 46].

All in all, no great difference in outcome between the two groups could be found. We expected that patients with better follow-up care specifically aimed at conservation of activities would ultimately result in better dependency in ADL, HRQOL and participation. Other research confirms this idea $[47,48]$ but these studies used small groups and mainly explored physical activity and the resources required to reconstruct their lives. However, ATC follow-up care seems of little added value compared to conventional followup care. In order to increase participation and improve QOL, a different type of follow up is required. Perhaps studying the individual needs of stroke patient would be more effective than a standard follow-up care programme. This needs further investigation in stroke patients.

\section{References}

1. Hoe vaak komt een beroerte voor en hoeveel mensen sterven eraan? Volksgezondheid Toekomst Verkenning, Nationaal Kompas Volksgezondheid Bilthoven . 2010. RIVM. Ref Type: Electronic Citation.

2. Bots ML, van Dis SJ: Factsheet Beroerte, Uitgave Nederlandse Hartstichting. 2006.

3. Hollander M, Koudstaal PJ, Bots ML, Grobbee DE, Hofman A, Breteler MM. Incidence, risk, and case fatality of first ever stroke in the elderly population. The Rotterdam Study. J Neurol Neurosurg Psychiatry. 2003;74(3):317321.
4. Feigin VL, Lawes CM, Bennett DA, Anderson CS. Stroke epidemiology: a review of population-based studies of incidence, prevalence, and case-fatality in the late 20th century. Lancet Neurol. 2003;2(1):43-53.

5. Verhoeven S, Beusmans GHMI, van Bentum STB, van Binsbergen JJ, Pleumeekers HJCM, Schuling J: NHGstandaard CVA. Huisarts Wet 2004, 47: 509-520.

6. Meyboom-de Jong B, Buis J: Zorg na een beroerte. Den Haag: Nederlandse Hartstichting; 1995.

7. Haacke C, Althaus A, Spottke A, Siebert U, Back T, Dodel R. Long-term outcome after stroke: evaluating health-related quality of life using utility measurements. Stroke. 2006;37(1):193-198.

8. Lee WC, Joshi AV, Wang Q, Pashos CL, Christensen MC. Morbidity and mortality among elderly Americans with different stroke subtypes. Adv Ther. 2007;24(2):258268.

9. Pham TM, Fujino Y, Tokui N, Ide R, Kubo T, Shirane $\mathrm{K}$, Mizoue T, et al. Mortality and risk factors for stroke and its subtypes in a cohort study in Japan. Prev Med. 2007;44(6):526-530.

10. D’Olhaberriague L, Litvan I, Mitsias P, Mansbach HH. A reappraisal of reliability and validity studies in stroke. Stroke. 1996;27(12):2331-2336.

11. de Haan R, Limburg M, Schuling J, Broeshart J, Jonkers L, van Zuylen P. [Clinimetric evaluation of the Barthel Index, a measure of limitations in dailly activities]. Ned Tijdschr Geneeskd. 1993;137(18):917-921.

12. Mahoney FI, Barthel DW. Functional Evaluation: The Barthel Index. Md State Med J. 1965;14:61-65.

13. Anderson C, Laubscher S, Burns R. Validation of the Short Form 36 (SF-36) health survey questionnaire among stroke patients. Stroke. 1996;27(10):1812-1816.

14. Unalan D, Soyuer F, Ozturk A, Mistik S. Comparison of SF-36 and WHOQOL-100 in patients with stroke. Neurol India. 2008;56(4):426-432.

15. Zee van der KI, Sanderman R: Het meten van de gezondheidstoestand met de RAND-36, Een handleiding. Noorderlijk Centrum voor Gezondheidsvraagstukken Rijksuniversiteit Groningen 2006..

16. Akritas MG: The rank transform method in some twofactor designs. J Am Stat Assoc 1990, 85.

17. Ekstam L, Uppgard B, von Koch L, Tham K. Functioning in everyday life after stroke: a longitudinal study of elderly people receiving rehabilitation at home. Scand J Caring Sci. 2007;21(4):434-446.

18. Kristensen HK, Persson D, Nygren C, Boll M, Matzen P. Evaluation of evidence within occupational therapy in stroke rehabilitation. Scand J Occup Ther. 2011;18(1):11-25.

19. Wallenbert I, Jonsson H. Waiting to get better: a dilemma regarding habits in daily occupations after stroke. Am J Occup Ther. 2005;59(2):218-224.

20. Chau JP, Thompson DR, Twinn S, Chang AM, Woo J. 
Determinants of participation restriction among community dwelling stroke survivors: a path analysis. BMC Neurol. 2009;9:49.

21. D’Alisa S, Baudo S, Mauro A, Miscio G. How does stroke restrict participation in long-term post-stroke survivors? Acta Neurol Scand. 2005;112(3):157-162.

22. Boosman H, Schepers VP, Post MW, Visser-Meily JM. Social activity contributes independently to life satisfaction three years post stroke. Clin Rehabil. 2011;25(5):460-467.

23. Edwards DF, Hahn M, Baum C, Dromerick AW. The impact of mild stroke on meaningful activity and life satisfaction. J Stroke Cerebrovasc Dis. 2006;15(4):151-157.

24. Hartman-Maeir A, Soroker N, Ring H, Avni N, Katz N. Activities, participation and satisfaction one-year post stroke. Disabil Rehabil. 2007;29(7):559-566.

25. Carod-Artal J, Egido JA, Gonzalez JL, Varela de Seijas E. Quality of life among stroke survivors evaluated 1 year after stroke: experience of a stroke unit. Stroke. 2000;31(12):2995-3000.

26. King RB. Quality of life after stroke. Stroke. 1996;27(9):1467-1472.

27. Murtezani A, Hundozi H, Gashi S, Osmani T, Krasniqi V, Rama B. Factors associated with reintegration to normal living after stroke. Med Arh. 2009;63(4):216-219.

28. Shyu YI, Maa SH, Chen ST, Chen MC. Quality of life among older stroke patients in Taiwan during the first year after discharge. J Clin Nurs. 2009;18(16):23202328.

29. Kauhanen ML, Korpelainen JT, Hiltunen P, Nieminen P, Sotaniemi KA, Myllyla VV. Domains and determinants of quality of life after stroke caused by brain infarction. Arch Phys Med Rehabil. 2000;81(12):1541-1546.

30. Therapy-based rehabilitation services for stroke patients at home. Cochrane Database Syst Rev. 2003;(1):CD002925.

31. Hartman-Maeir A, Eliad Y, Kizoni R, Nahaloni I, Kelberman H, Katz N. Evaluation of a long-term community based rehabilitation program for adult stroke survivors. NeuroRehabilitation. 2007;22(4):295-301.

32. Legg L, Langhorne P. Rehabilitation therapy services for stroke patients living at home: systematic review of randomised trials. Lancet. 2004;363(9406):352-356.

33. Ryan T, Enderby P, Rigby AS. A randomized controlled trial to evaluate intensity of community-based rehabilitation provision following stroke or hip fracture in old age. Clin Rehabil. 2006;20(2):123-131.

34. StalenhoefAF. [Secondary prevention of recurrent stroke by lowering cholesterol levels and blood pressure]. Ned Tijdschr Geneeskd. 2006;150(39):2127-2130.

35. Giesen AGM, Franke CL, Wiersma TJ, Binsbergen van JJ, Boiten J, Flikweert S et al.: Landelijke Transmurale
Afspraak TIA/CVA. Huisarts Wet 2004, 521-526.

36. CBO: Richtlijn Beroerte. Utrecht: CBO 2000.

37. Multidisciplinaire werkgroep aangesteld door CBO: NHG-standaard Cardiovasculair risicomanagement. NHG-standaarden voor de huisarts 2007.

38. Cifu DX, Stewart DG. Factors affecting functional outcome after stroke: a critical review of rehabilitation interventions. Arch Phys Med Rehabil. 1999;80(5 Suppl 1):S35-39.

39. Pollock A, Baer GD, Langhorne P, Pomeroy VM. Physiotherapy Treatment Approaches for Stroke. Stroke. 2008.

40. Pollock A, Baer G, Langhorne P, Pomeroy V. Physiotherapy treatment approaches for the recovery of postural control and lower limb function following stroke: a systematic review. Clin Rehabil. 2007;21(5):395-410.

41. Harrington R, Taylor G, Hollinghurst S, Reed M, Kay $\mathrm{H}$, Wood VA. A community-based exercise and education scheme for stroke survivors: a randomized controlled trial and economic evaluation. Clin Rehabil. 2010;24(1):3-15.

42. Appelros P, Nydevik I, Viitanen M. Poor outcome after first-ever stroke: predictors for death, dependency, and recurrent stroke within the first year. Stroke. 2003;34(1):122-126.

43. Bamford J, Sandercock P, Dennis M, Burn J, Warlow C. A prospective study of acute cerebrovascular disease in the community: the Oxfordshire Community Stroke Project--1981-86. 2. Incidence, case fatality rates and overall outcome at one year of cerebral infarction, primary intracerebral and subarachnoid haemorrhage. J Neurol Neurosurg Psychiatry. 1990;53(1):16-22.

44. Smajlovic D, Kojic B, Sinanovic O. Five-year survival-after first-ever stroke. Bosn J Basic Med Sci. 2006;6(3):17-22.

45. Nedeltchev K, Renz N, Karameshev A, Haefeli T, Brekenfeld C, Meier N, Remonda L, et al. Predictors of early mortality after acute ischaemic stroke. Swiss Med Wkly. 2010;140(17-18):254-259.

46. Wu B, Lin S, Hao Z, Yang J, Xu Y, Wu L, Zhang S, et al. Proportion, risk factors and outcome of lacunar infarction: a hospital-based study in a Chinese population. Cerebrovasc Dis. 2010;29(2):181-187.

47. Reed M, Harrington R, Duggan A, Wood VA. Meeting stroke survivors' perceived needs: a qualitative study of a community-based exercise and education scheme. Clin Rehabil. 2010;24(1):16-25.

48. Marsden D, Quinn R, Pond N, Golledge R, Neilson C, White $\mathrm{J}$, McElduff $\mathrm{P}$, et al. A multidisciplinary group programme in rural settings for community-dwelling chronic stroke survivors and their carers: a pilot randomized controlled trial. Clin Rehabil. 2010;24(4):328-341. 